\title{
Radiological appearances of lymphangitis carcinomatosa of the lung
}

\author{
D A V I D H. TR A P N ELL \\ From the Department of Diagnostic Radiology, St. Batholomew's Hospital, London ${ }^{2}$
}

Malignant tumours commonly metastasize to the lungs. When they do, the secondary deposits are usually in the form of discrete nodules which have no particular relationship to lymph nodes or vessels. Occasionally, however, the tumour spread may predominantly or exclusively affect the lymphatic system of the lungs. Andral (1829), Virchow (1855), and Wagner (1863) were among the first to describe this form of metastatic involvement of the lungs. Troisier (1873) demonstrated a case of carcinoma of the stomach with permeation of the superficial and deep lymphatics of both lungs ('lymphangite pulmonaire') by yellowish tumour tissue. In the discussion that followed, Charcot (1873) commented that this case threw new light on the mode of spread of cancer, but Debove (1874) stated that tumour spread by lymphatics had been known to surgeons for a long time. Raynaud (1874) described another case, also with a carcinoma of the stomach, which he called 'angioleucite' (lymphangitis). He defended the use of this term on the grounds that all the signs of inflammation were present, but he admitted by inference that this permeation of the lymphatics by tumour was not really an inflammatory process.

Since these early descriptions the name, even though inept, has persisted. The condition is well known to pathologists and, as Harold (1952) suggested, occurs more frequently than might be supposed from the scarcity of published cases. $\mathrm{He}$ could find only 154 cases in the medical literature for the years 1840 to 1950 , but he was able, at two hospitals, to collect 24 new cases in a period of four years, 13 of these being from 170 necropsy examinations for malignant disease. The British literature on the subject has been scanty (Bristowe, 1868 ; Bennett, 1871 ; Lorain Smith, 1909 ; Wu, 1936 ; Morgan, 1949 ; Harold, 1952 ; Chandler and Telling, 1952 ; Beattie, 1956).

The radiological features of the disease have received particularly little study. The first workers to describe these were Assmann $(1914 ; 1929)$ and Lorenz (1921), who emphasized increased pro-

\footnotetext{
1 Present address: Wsstminster Hospital, London, S.W.1.
}

minence of the 'lung markings,' by which it appears that they meant the pulmonary vascular shadows. They also noted numerous small nodular opacities which were attributed to tumour-filled lymphatics 'cut' end-on by the incident $x$-ray beam. The density of the hila was increased in their cases. Although some workers (Mueller and Sniffen, 1945) have suggested that in drawing attention to the fine linear shadows spreading from the hilum they attributed these to tumour-filled lymphatics, this does not appear to be the case. Indeed, Assmann (1929), commenting on the work of Franke (1912), who had injected pulmonary lymphatics, concluded that the lymphatics of the lung were so closely related to the arteries that it would be impossible to distinguish them from the blood vessels radiographically.

Mueller and Sniffen (1945) reported the radiological findings in 10 cases, the diagnosis of seven of which had been proved at necropsy. They confirmed the findings of Assmann $(1914,1929)$ and Lorenz (1921), noting both a streaky, string-like network of shadows spreading from the hila into the lungs and 'miliary' nodular opacities in the lung field. They noted that these changes were usually more marked at the bases and, as in a case of bronchial carcinoma, might be unilateral. Mueller and Sniffen attributed these radiological changes predominantly to involvement of the deep lymphatics within the lung, rather than of the pleural ones on its surface. Invasion of the walls of the pulmonary arteries and bronchi by tumour was held to play a negligible part in the formation of the radiographic appearances. They considered that fibrosis, oedema, and vascular congestion were not present in sufficient amount in their cases to produce visible changes in the radiographs. Pleural effusions were small and uncommon, but hilar node enlargement was 'obvious' in most of their cases. Harold (1952) and Beattie (1956) did not add to the descriptions of the radiological appearances given by earlier workers. In one case reported by Harold (1952), there was no detectable abnormality in the chest radiograph until death. 
In 1951 Kerley made an important contribution to the interpretation of chest radiographs when he described ' $A$ ' and ' $B$ ' lines in silicosis and suggested that they were the shadows cast by distended lymphatics. Interest in these lines at first centred upon their presence and significance in mitral stenosis, but it was not long before they were also recognized in other conditions, including lymphangitis carcinomatosa (Grainger, 1958; Levin, 1959).

The purpose of this study is to determine the radiological abnormalities present in lymphangitis carcinomatosa and to discover whether any association of these constitutes a 'typical' and recognizable appearance. In particular, attention has been given to the incidence and significance of ' $A$ ' and ' $B$ ' lines. To determine the cause of the abnormal shadows seen in the radiographs, in some cases a correlation was made with the histo- logical appearance of the lesions causing them by radiographic studies of the lung after death.

\section{MATERIAL AND METHODS}

In order to study the radiological appearances of lymphangitis carcinomatosa all the available chest radiographs of 20 patients with this condition, later confirmed at necropsy, were examined. In all the cases studied there was macroscopic permeation of the pleural and deep lymphatics, this also being confirmed histologically. Other cases, with 'typical' radiological changes but no pathological proof, were not included. The incidence of ' $A$ ' and ' $B$ ' lines was noted and the presence of other radiological abnormalities was also recorded.

The recognition of ' $A$ ' and ' $B$ ' lines has been based upon the following definitions which have been slightly amplified from the original description by Kerley (1951). Lines were called ' $A$ ' when they were fine (less than $1 \mathrm{~mm}$. thick) and straight, or very nearly

FIG. 1. (a) $A$ reproduction (original size) of the radiograph of the right mid-zone showing ' $A$ ' lines (arrowed). Male, aged 46, a few weeks before his death from carcinoma of the stomach with lymphangitis carcinomatosa involving both lungs. (b) Part of the left lower zone (original size) showing ' $B$ ' lines (arrowed).

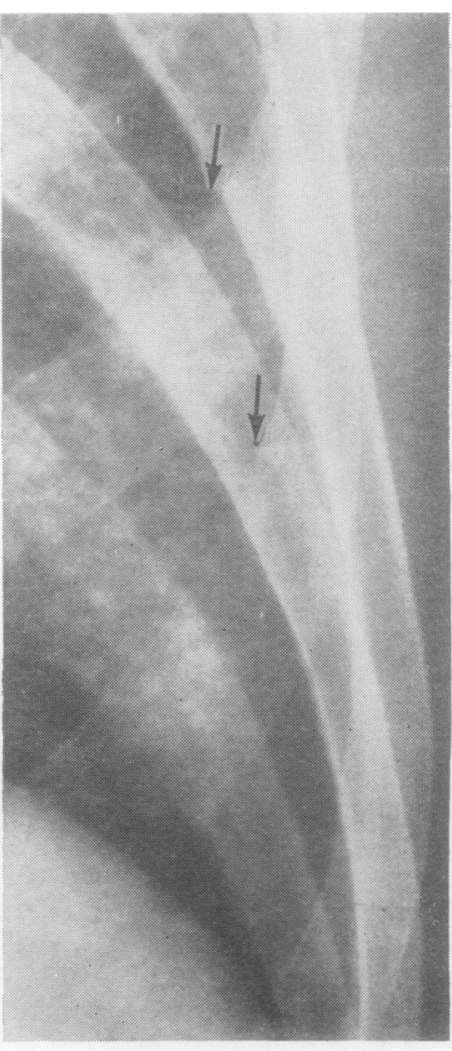

(b) 


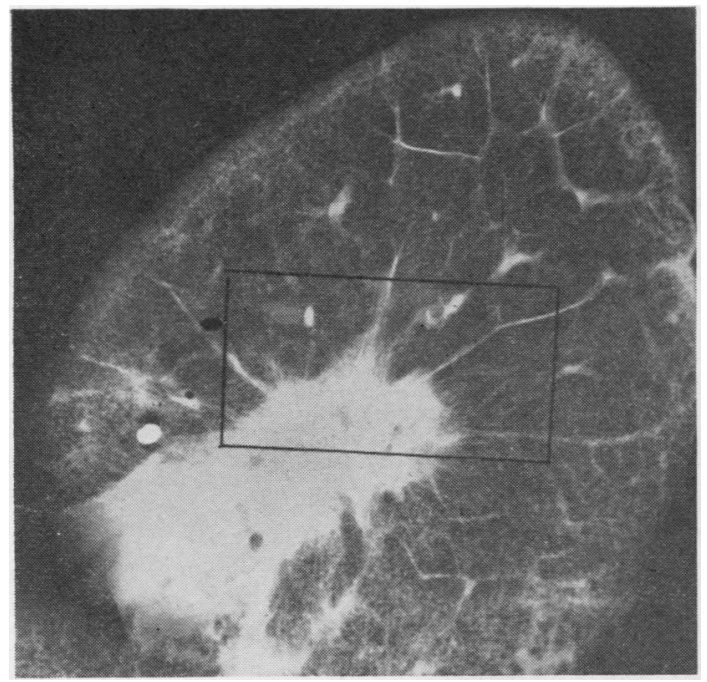

FIG. 2. Radiograph of a slice approximately $1 \mathrm{~cm}$. thick of the right upper lobe of the lung seen in Fig. 4 showing the primary tumour and linear shadows spreading into the lung from it. The area ringed was removed for histological examination and the line extending to the right is shown in Fig. 5.

so, when they pointed towards the hilum and did not branch: they did not touch the pleura and were usually at least $2 \mathrm{~cm}$. in length, although none longer than $4 \mathrm{~cm}$. was seen (Fig. 1a).

'B' lines were approximately perpendicular to the pleural surface of the lung and always touched the pleura at their outer ends. They were fine (less than $1 \mathrm{~mm}$. thick), straight and short, and usually less than $2 \mathrm{~cm}$. long (Fig. 1b). Linear shadows, which were not at right angles to the pleura, or did not touch it, or were not virtually straight, were not recorded as ' $B$ ' lines. All lines that branched or were thicker than $1 \mathrm{~mm}$., and all linear shadows longer than $2.5 \mathrm{~cm}$. that touched the pleura were not regarded as ' $A$ ' or 'B' lines.

A special study of the lungs of five of these patients was made at necropsy using radiography and gaseous fixation (Cureton and Trapnell, 1961). In these cases the whole lung was radiographed in several different positions immediately after inflation. After fixation it was cut into slices about $1 \mathrm{~cm}$. thick, and radiographs were then made of each slice (Figs. 2 and 3 ). In this way it was possible to locate quite small lesions causing shadows in the radiographs and to remove the appropriate part of the lung for histological examination.

\section{FINDINGS}

CHEST RADIOGRAPHS OF LIVING PATIENTS The findings on each side of the thorax in all the available chest radiographs of the 20 patients in this series were recorded separately. In addition

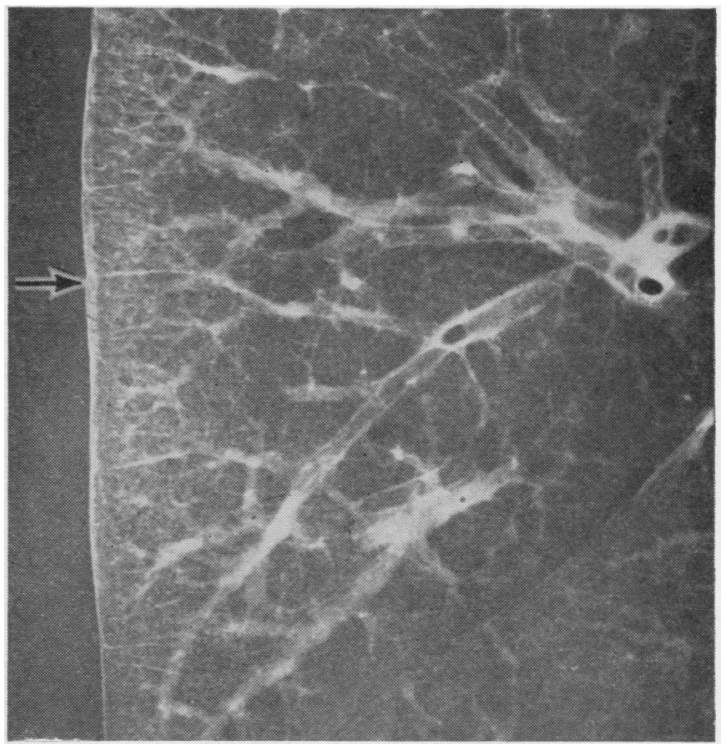

FIG. 3. Part of a radiograph of a slice approximately $1 \mathrm{~cm}$. thick of the lung shown in Fig. 10. Several ' $B$ ' lines are shown. The structure causing one of these (arrowed) was removed for histological examination.

to noting the presence or absence of an abnormality, an attempt was made to indicate the severity or extent of the changes by arbitrarily dividing each lung field into three zones, upper, middle, and lower, and recording the number of zones showing the abnormality. The results are shown in the Table. Thus it will be seen, for

T A B L E

EXAMINATION OF CHEST RADIOGRAPHS OF 20 PATIENTS

\begin{tabular}{|c|c|c|c|c|}
\hline \multirow{2}{*}{$\begin{array}{c}\text { Radiological } \\
\text { Abnormality } \\
\text { Present }\end{array}$} & \multicolumn{2}{|c|}{ Cases } & \multicolumn{2}{|c|}{ Total Zones Involved } \\
\hline & No. & $\%$ & Right & Left \\
\hline $\begin{array}{l}\text { 'A' lines } \quad \ldots \\
\text { 'B' lines } \\
\text { Nodular shadows }\end{array}$ & $\begin{array}{r}11 \\
6\end{array}$ & $\begin{array}{l}55 \\
30\end{array}$ & $\begin{array}{l}8 \\
4\end{array}$ & $\begin{array}{l}5 \\
2\end{array}$ \\
\hline $\begin{array}{l}\text { (<1 cm. diam.) .. } \\
\text { Diffuse clouding ... } \\
\text { Pleural effusion } \\
\text { Hilar node enlarge- }\end{array}$ & $\begin{array}{l}19 \\
13 \\
11\end{array}$ & $\begin{array}{l}95 \\
65 \\
55\end{array}$ & $\begin{array}{l}36 \\
23 \\
12\end{array}$ & $\begin{array}{r}30 \\
10 \\
9\end{array}$ \\
\hline $\begin{array}{l}\text { ment } \\
\text { Large opacities }(>1\end{array}$ & 8 & 40 & 6 & 6 \\
\hline $\begin{array}{l}\text { cm. diam.) } \\
\text { Thickening of lesser }\end{array}$ & 6 & 30 & 6 & 2 \\
\hline fissure $\quad \ldots \quad \ldots$ & 9 & 45 & 9 & \\
\hline
\end{tabular}

example, that nodular shadows were present in 19 patients and that, on average, each patient had two zones of the right lung involved.

' A' lines (Fig. 1a) were more common than 'B' lines (Fig. 1b). Abnormalities were more com. mon in the right lung than in the left, partly because four of the five cases showing unilateral 


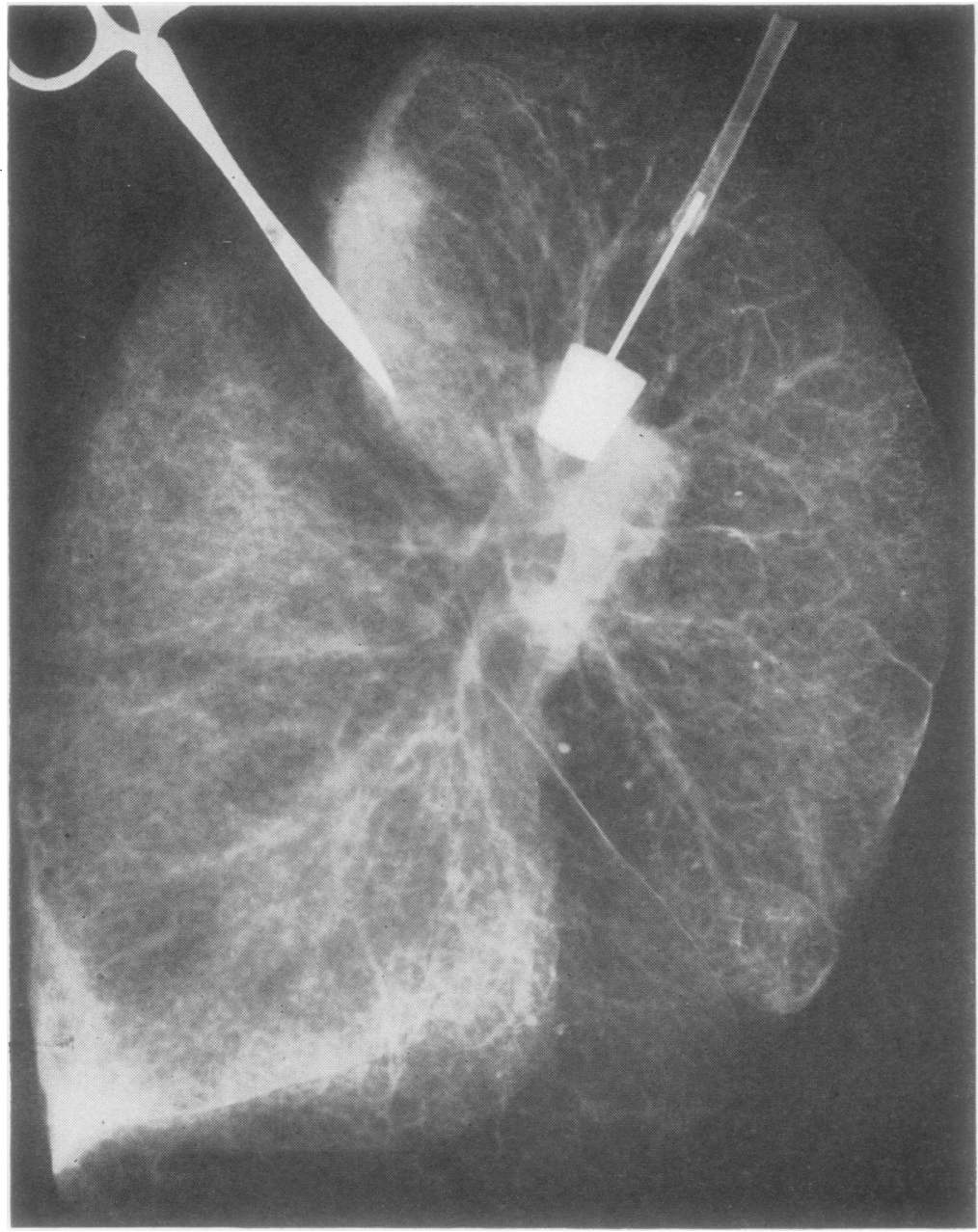

FIG. 4. Radiograph of the whole right lung of a woman aged $59 \overrightarrow{\vec{\omega}}$ years, who died of carcinoma of $\mathrm{\omega}$ the bronchus, the site of which is shown by the forceps (compare Fig. 9).

changes were on the right. Even so, there was a slight predominance of abnormalities in the right lung. ${ }^{1}$ For example, excluding the five unilateral cases, the number of zones showing ' $A$ ' lines was six on the right and four on the left.

\section{NECROPSY EXAMINATION OF LUNGS (5 PATIENTS)}

Radiological Radiography of the intact lung of one case (Fig. 4) showed fine, linear shadows, resembling ' $A$ ' lines, spreading from the main tumour mass. When a radiograph of a slice of the lung approximately $1 \mathrm{~cm}$. thick was made, these

\footnotetext{
1 Because the lymphatics from the left lower lobe cross in the mediastinum to the subcarinal and right paratracheal lymph nodes (Rouvière, 1932; Nohl, 1962), it seems possible that tumour cells from the left lung may obstruct the lymphatic drainage from the right lung, first causing oedema in it and then permitting the retrograde spread of tumour cells into it. In this series there was no evidence that a left lung tumour caused changes in the right lung.
}

radiating lines were clearly revealed (Fig. 2). Histological examination of one of these (Figs. 5 and 6) showed that the deep lymphatics were permeated by tumour cells and that around them there was a fibrotic reaction, most of the thickness of the line being due to the fibrous tissue. In the same lung, ' $B$ ' lines were numerous, particularly in the lower lobe, and the histological appearance of the interlobular septa causing them was similar to that of the lines near the primary tumour in the upper lobe. In other cases (Figs. 7 and 8), little surrounding fibrosis was present. Figure 7 shows how the composition and thickness of an interlobular septum, which caused a 'B' line (Fig. 3) in a radiograph of the lung after fixation, may vary. Some of the increased width of the septum is due to tumour-filled lymphatics and some is due to a 


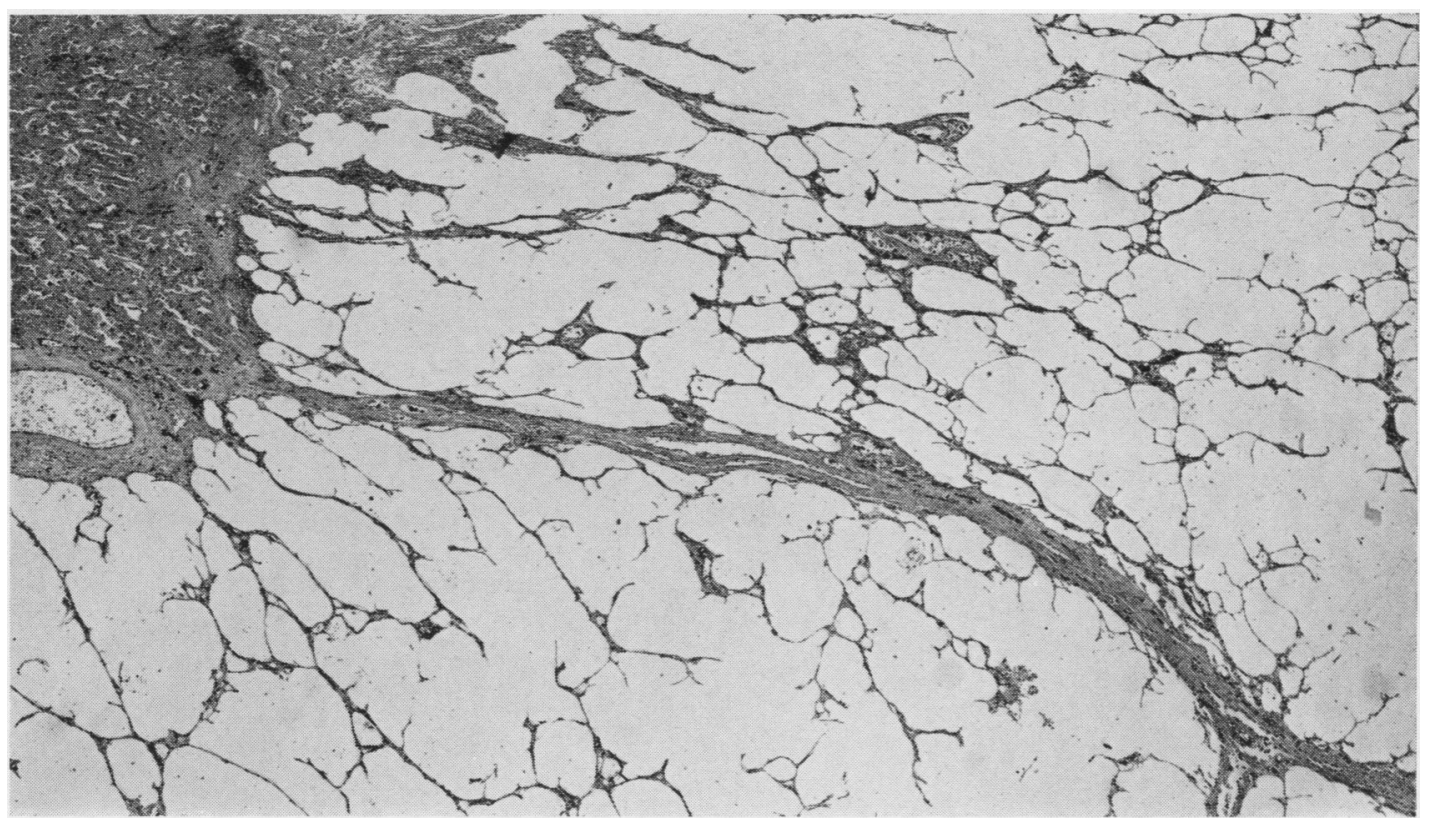

FIG. 5. Photomicrograph of the part of the lung causing the linear shadow shown in Fig. 2. Haematoxylin and eosin, $\times 15$.

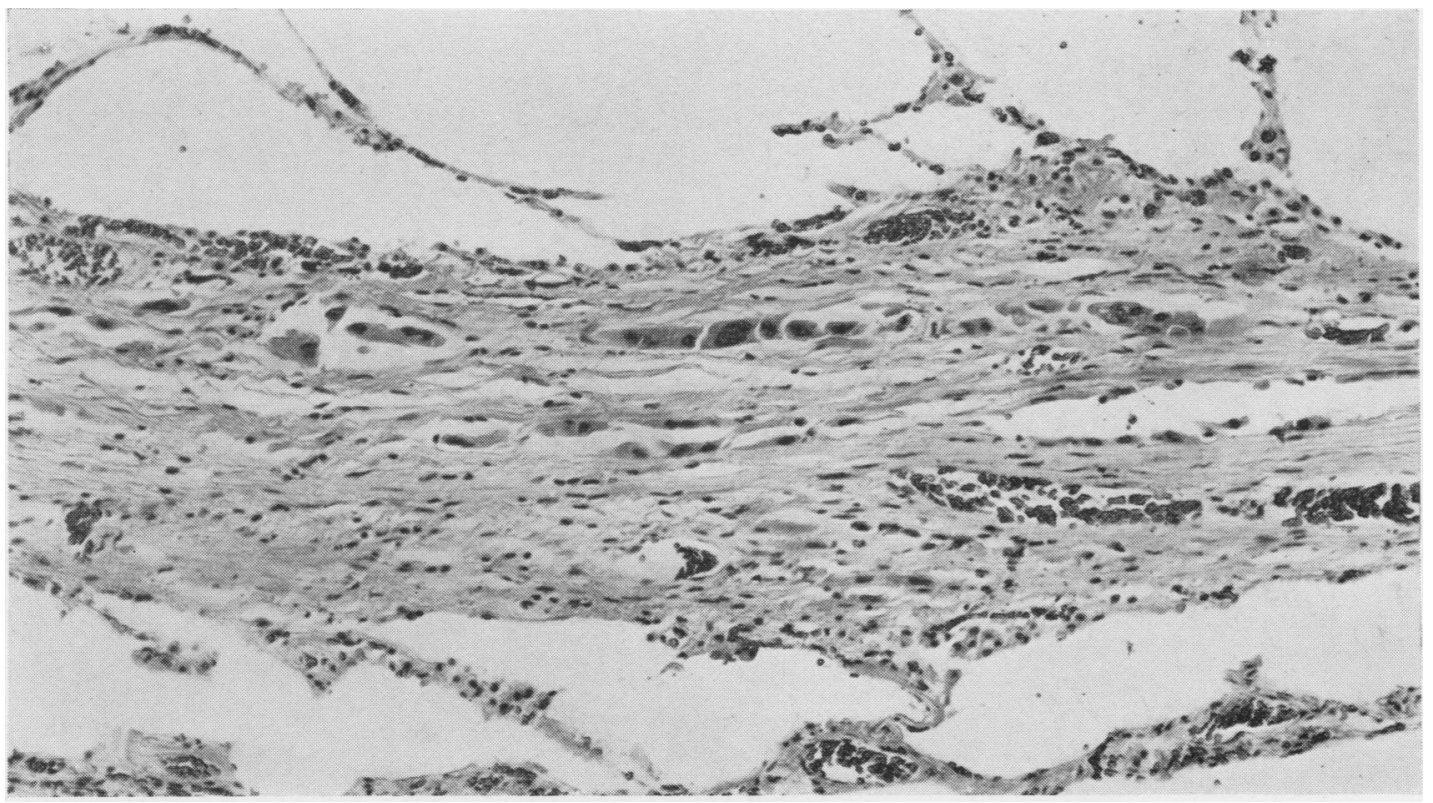

FIG. 6. Photomicrograph of part of the same line as in Fig. 5 showing small lymphatics, containing tumour cells, surrounded by fibrous tissue and some chronic inflammatory cells. Haematoxylin and eosin, $\times 155$. 


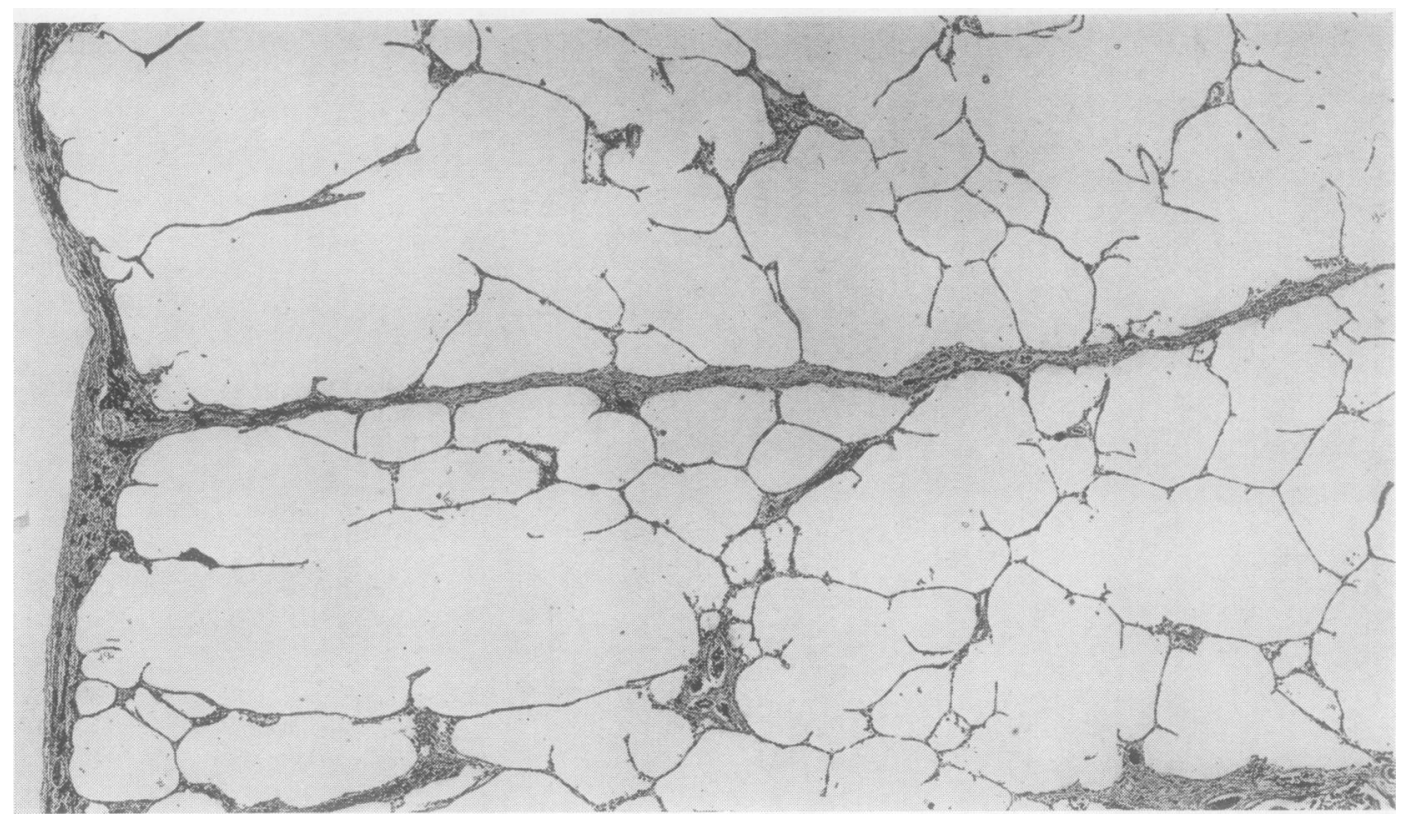

FIG. 7. Photomicrograph of the structure arrowed in Fig. 3 which is shown to be an interlobular septum containini small lymphatics permeated by a tumour and surrounded by fibrous tissue. Haematoxylin and eosin, $\times 22$.

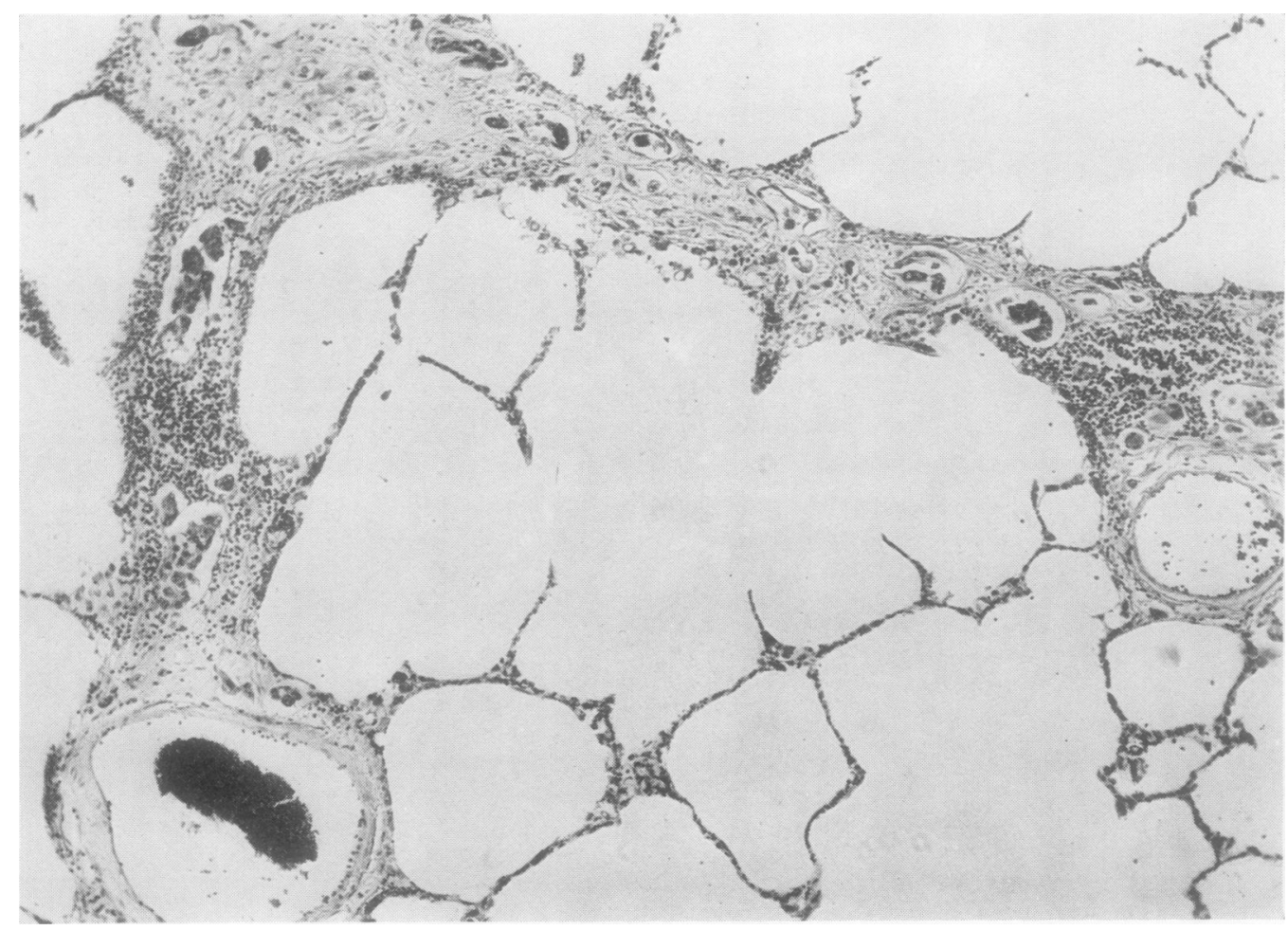

FIG. 8. Photomicrograph of part of an interlobular septum. Haematoxylin and eosin, $\times 85$. 
fibrous reaction and infiltration with lymphocytes. When such septa are tangential to the $x$-ray beam, they cast linear shadows, but the variation in the thickness in different planes is lost in the summations of these shadows (Fig. 8).

No other lines were visible in any of the radiographs of the whole lung or slices of it in the five cases examined post mortem. In two cases a thin slice of the surface of part of the lung showing pleural lymphatics permeated by tumour was placed in contact with fine-grain $x$-ray film and radiographed. The pleural lymphatics did not cast any recognizable shadows even under these ideal conditions.

Pathological Tumour permeation of the pleural lymphatics produces a characteristic appearance (Fig. 9). In early cases the lung is normal in size, inflates without difficulty, and, when inflated, presents a smooth surface with the superficial lymphatics clearly shown as a fine, whitish net-work on it. In more chronic cases the lung is small and is distended only with difficulty. When it is inflated the lobules of the lung bulge out between the interlobular septa (Fig. 9). On cutting such a lung it is apparent that in these cases there is thickening and rigidity of the interlobular septa which prevents normal expansion of the lung. This may be confirmed by microscopy which shows that, in addition to the tumour-filled lymphatics, there is much fibrosis around the lymphatics of the interlobular septa and those beside the bronchi and blood vessels.

The distribution of the pleural lymphatics as 'injected' naturally with tumour cells corresponds with that seen in the living lung at operation and in injected specimens after death (Trapnell, 1963). Visible pleural lymphatics are far more common over the lower lobe, including its upper part, than they are in the upper lobe or middle lobe, even in the lowermost parts of the lingula. Occasionally a few tumour-filled lymphatics can be seen running a short course in the pleura of the upper lobe. The distribution of the interlobular, perivenous, and peribronchial lymphatics, on the other hand, appears to be approximately equal in all parts of the lung.

Valves may sometimes be visible on macroscopic or microscopic examination of the pleural lymphatics, but less commonly than in injected specimens, presumably because the valves are damaged by the tumour. This is not always the case, however. Figure 10 shows a photomicrograph of an
FIG. 9. Part of the lower lobe (original size) of the lung shown in Fig. 4 showing the pleural lymphatics and irrcgularity of the surface of the lung caused by fibrosis in the interlobular septa.

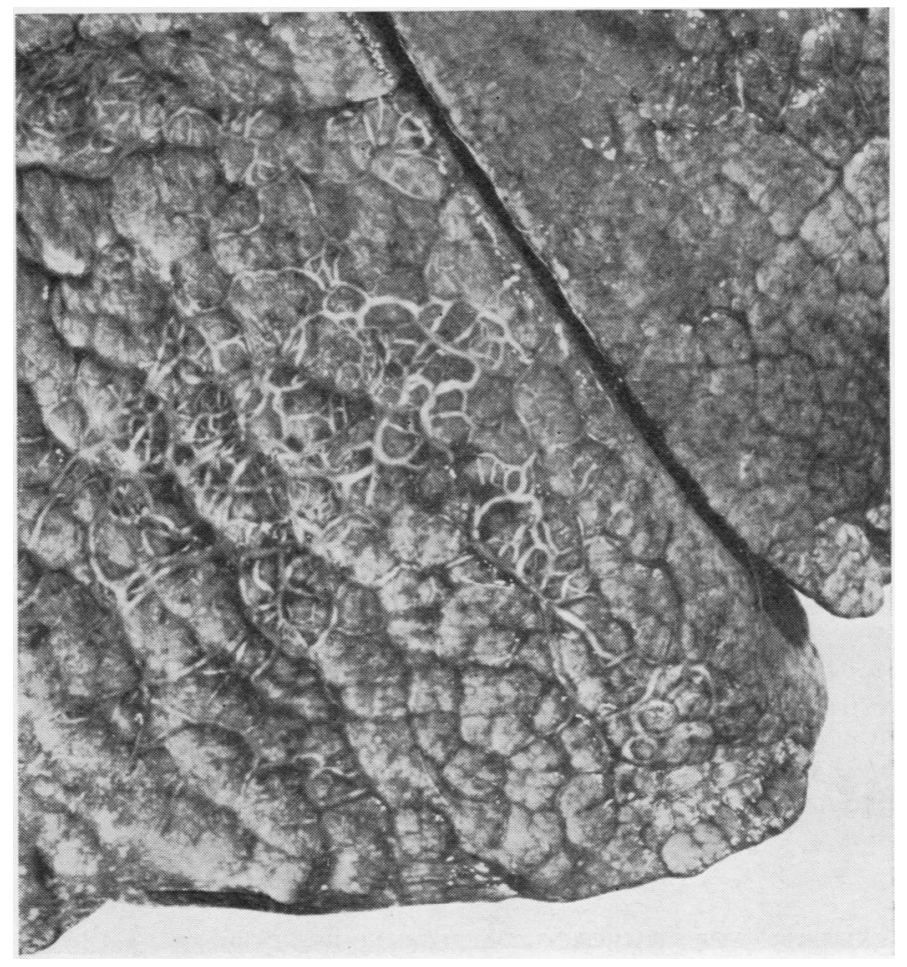




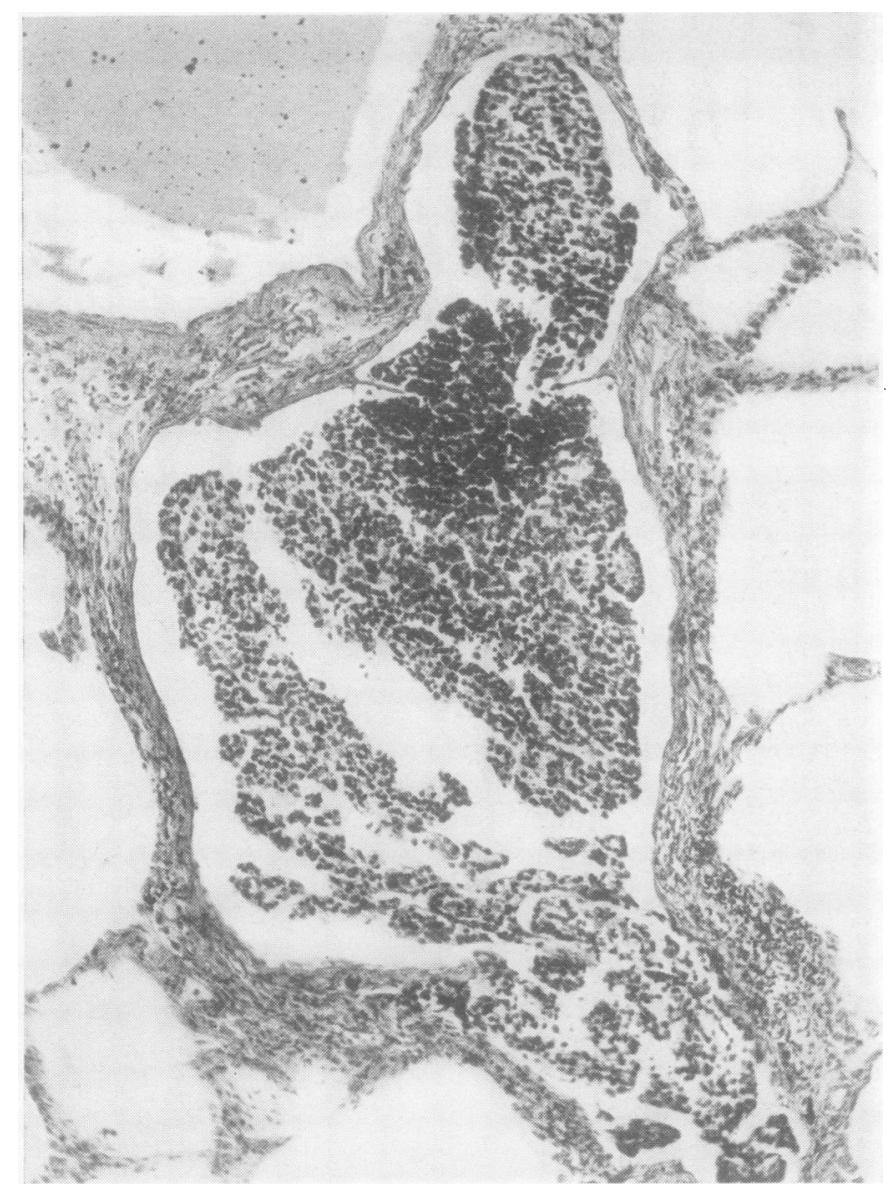

FIG. 10. Photomicrograph of an interlobular lymphatic containing tumour cells and showing a valve which points away from the pleura. There is only a little surrounding fibrosis and a small round cell infiltration. Haematoxylin and eosin, $\times 95$.

interlobular lymphatic permeated by tumour cells and a valve, the (normal) cusps of which point towards the hilum. Sometimes, if the lymphatics of cases of lymphangitis are injected after death with a microscopically recognizable medium, clumps of tumour cells can be shown lying free in a lymph vessel surrounded by the injection medium.

In this series of 20 cases, the site of the primary tumour was the bronchus (8), breast (7), stomach (4), and colon (1). In five patients the lymphangitis was unilateral, all being cases with a carcinoma of the bronchus and lymphatic permeation in the same lung only. In two of the five patients whose lungs were radiographed at necropsy, discrete nodules of tumour deposit were scattered in the lung tissues in addition to the lymphatic permeation.

\section{DISCUSSION}

CRITERIA FOR RADIOLOGICAL DIAGNOSIS DURING LIFE No single radiological abnormality out of those mentioned above (Table) can be used as a basis for diagnosing permeation of the pulmonary lymphatics by tumour. Any of these may form part of the radiological picture in a number of different disorders. The presence of bone metastases did not help to determine whether lymphatic permeation was present or not. There is, however, a 'characteristic' radiographic appearance present in about half the cases but the changes may only be present late in the course of the disease. This consists of the presence of ' $A$ ' lines, often in the upper or middle zones, with hilar node enlargement, fine nodular shadowing in several zones and, sometimes, 'B' lines, a pleural effusion or tumour masses. If this picture is seen, the diagnosis of lymphangitis carcinomatosa should at least be considered. If no heart failure is present and there is no history of exposure to an industrial dust hazard, the diagnosis should be suggested by the radiologist even though malignant disease may not have been suspected by the clinician. 
Grainger (1958) reported that unilateral tumour permeation of the pulmonary lymphatics is rare. It is interesting to note, therefore, that his case and that described by Mueller and Sniffen (1945), like the five unilateral cases in this series, were all due to carcinoma of the bronchus. Thus, if the radiological appearances suggest lymphangitis carcinomatosa, but of one lung only, even though a definite primary tumour mass may not be visible, carcinoma of the bronchus should be seriously considered as a cause. This association between unilateral lymphangitis carcinomatosa and carcinoma of the bronchus in the same lung does not seem to have been described before. Hauser and Steer (1951) described what appears to be the only recorded instance of unilateral lymphangitis carcinomatosa not due to carcinoma of the bronchus, and this was from an adenocarcinoma of the rectum. In their case the patient had had a left thoracoplasty for tuberculosis, and the lung on that side was compressed but contained no tumour tissue. The functioning right lung had discrete tumour nodules in it and the pleural lymphatics were permeated by tumour cells. Apart from one of the cases in the present series, all those described have involved the right lung.

THE CAUSE OF ' $A$ ' AND ' $B$ ' LINES ' $B$ ' lines are caused not by a distended lymphatic alone but by the whole interlobular septum. Its thickness varies from point to point (Fig. 7) but summation of the various thicknesses, when the septum is tangential to the $x$-ray beam, results in a linear shadow of approximately even thickness. There was only one lung in the five cases of this series that had lines that might be called ' $A$ ' lines. These proved at necropsy to be due, like ' $B$ ' lines, to numerous small lymph channels containing tumour surrounded by a relatively much thicker layer of fibrous tissue and small round cell infiltration (Figs. 5 and 6). Because a lymphatic, whether or not it is surrounded by fibrous tissue, can only cast a distinct shadow in the radiograph when it has air on each side of it (to provide negative contrast), ' $A$ ' lines must be due to those lymphatics that are separate from other structures, such as blood vessels or bronchi, if they are caused by lymphatics at all. A study of radiographs of lungs in which the lymph vessels had been outlined with a radiopaque medium showed that 'anastomotic' lymphatics are common, running an independent course through lung tissue between pulmonary veins and the bronchi (Trapnell, 1963). It seems likely that such lymphatics, when they are surrounded by abnormal tissue like that shown in Fig. 6 , may be the cause of ' $A$ ' lines. It is import- ant to appreciate, however, that the actual lymph vessels play only a small part in causing ' $A$ ' or ' $B$ ' lines, and that the greater part in lymphangitis carcinomatosa is due to the surrounding fibrous tissue and cellular infiltration.

If associated left ventricular failure is present it is theoretically possible that ' $A$ ' or ' $B$ ' lines might be present due to this as well. In fact, however, this seems to be uncommon, the symptoms and physical signs being predominantly due to respiratory embarrassment or right ventricular failure, which does not cause ' $A$ ' or ' $B$ ' lines. Another possible contributing factor in the production of ' $A$ ' and ' $B$ ' lines may be the oedema that is present without heart failure in some cases of lymphangitis carcinomatosa and which was presumably the cause of the diffuse clouding present in 13 of the 20 cases. In none of the five lungs radiographed, where it was possible to correlate the radiological and histological appearances, was there any positive evidence that this does in fact occur.

THE CAUSE OF OTHER RADIOLOGICAL ABNORMALITIES Apart from ' $A$ ' and ' $B$ ' lines, the changes found in lymphangitis carcinomatosa are of less diagnostic importance. Pleural effusion, discrete metastases, oedema, and hilar node enlargement need no special comment. In two cases of this series a shadow, later proved to be due to the primary bronchial carcinoma, was also visible.

Thickening of the lesser fissure is a sign of more interest in that its cause is not certain. It was mentioned by Simon (1962), who considered that it may be due to tumour-filled pleural lymphatics running towards the hilum in the fissure. There was no tumour permeation of lymphatics under the pleura of either lobe adjacent to the fissure in the only lung examined at necropsy that had shown thickening of the fissure during life. Three other right lungs were studied from cases where there had been no demonstrable thickening of the fissure before death. One had tumour masses in both lobes but, like the two other cases, there was no permeation of the pleural lymphatics in the fissure. In a study of 13 right lungs after the injection of all visible pleural lymphatics (Trapnell, 1963), there was no case in which a pleural lymphatic was shown in the pleura of either lobe forming the fissure. It seems therefore that tumour permeation of the pleural lymphatics is not likely to be the cause of the thickening of the fissure. Alternative explanations are that it is caused by a small amount of oedema in the pleura, such as may occur in cardiac failure (Short, 1956), but no evidence was found to support this; or that the thickening is caused by a small amount of fluid in 
the fissure. Of the nine cases that had thickening of the fissure during life, only two had any other evidence of a pleural effusion so that this is also an unlikely cause. Thus there was no positive evidence in this series to indicate the cause of the thickening of the lesser fissure that was present in nearly half of the cases.

Small nodular shadows were noted in the antemortem chest radiographs of 19 of the 20 cases studied. Similar opacities were described by Assmann (1914, 1929), Lorenz (1921), and Mueller and Sniffen (1945). They attributed these fine shadows to tumour-filled lymphatics 'cut' end-on by the incident $x$-ray beam. The nodular opacities in the cases seen personally were sometimes so numerous that this seems unlikely to be the whole explanation. Carstairs (1961) showed that, if layers of a simple plastic lattice were superimposed and radiographed, a nodular type of shadow resulted. He showed in effect that many interlacing strands of plastic (all parallel to the $x$-ray film) cast a composite mottled shadow which might be interpreted as indicating that nodules were present or that the plastic lattice had been end-on to the $x$-ray beam. The same appearances may presumably be caused by the superimposition of the shadows of many tumour-filled lymphatics. This simple physical phenomenon seems to be the probable explanation of most, if not all, of the fine nodular opacities seen in lymphangitis carcinomatosa because radiographs of the slices of the lungs showed no such nodular shadows.

\section{SUMMARY}

The chest radiographs of 20 patients, subsequently proved at necropsy to have lymphangitis carcinomatosa, were examined. Abnormalities were found to be slightly more common in the right lung than in the left. No single radiographic change was diagnostic but the combination of abnormalities was sufficiently characteristic to suggest the diagnosis in about half the cases.

The lungs of five of these patients were studied radiographically and histologically at necropsy. It was shown that tumour-filled pleural lymphatics cast no recognizable shadow and that ' $B$ ' lines are due to the interlobular septa, thickened by fibrous and inflammatory tissue around tumourstuffed lymphatics. 'A' lines appear to be due to 'anastomotic' lymphatics, which run an independent course through the lung, when they are similarly surrounded by fibrous tissue and chronic inflammatory cells.

The pathological cause of some of the other radiological abnormalities is also discussed.
I am indebted to the physicians and surgeons of $\overrightarrow{\vec{N}}$ St. Bartholomew's Hospital, and to Mr. E. S. Lee, Westminster Hospital, for permission to study their cases, to the pathologists who removed the lungs at $\overline{\bar{n}}$ necropsy and, particularly, to Dr. R. J. R. Cureton for his help with the selection and interpretation of $\stackrel{\mathbb{Q}}{\varrho}$ the histological material. I am very grateful to the Department of Medical Photography, St. Bartholomew's Hospital, for reproduction of the radiographs. to Mr. P. J. Crocker for the photomicrographs, and to Mr. J. W. Miller for the histological preparations.

\section{REFERENCES}

Andral, G. (1829). Précis d'Anatomie Pathologique, Vol. 2, p. 444, $\omega$ Gabon, Paris. Quoted by Mueller, H. P., and Sniffen, R. C. N (1945).

Assmann, H. (1914). Erfahrungen über die Röntgenuntersuchungen der Lungen, p. 117. Fischer, Jena (Arb. med. Klin. Leipzig, Hcft 2)응

Quoted by Assmann, H. (1929).
(1929). Die klinische Röntgendiagnostik der inneren Erkran- kungen, 4th ed., pp. 257, 354, 355. Vogel, Leipzig. Beattie, J. W. (1956). Lymphangitis carcinomatosa. Brit. J. Tuberc.,

Bennett, J. R. (1871). Secondary scirrhous, or fibro-cancerous, $\vec{A}$ infiltration of connective tissue of lung, etc.; primary cancer of $\vec{\theta}$

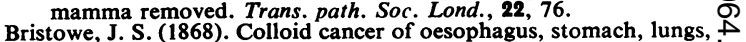
and adjoining lymphatic glands. Ibid., 19, 228.

Carstairs, L. S. (1961). The interpretation of shadows in a restricted area of a lung field on the chest radiograph. Proc. roy. Soc. Med., 54, 978.

Chandler, G. N., and Telling, M. (1952). Lymphangitis carcinomatosa. Brit. med. J., 2, 639.

Charcot (1873). Bull. Soc, anat. Paris, 48, 836.

Cureton, R. J. R., and Trapnell, D. H. (1961). Post-mortem radiography and gaseous fixation of the lung. Thorax, 16, 138.

Debove (1874). Note sur les lymphangites cancéreuses. Progr. méd. (Paris), 2, 61.

Franke, K. (1912). Über die Lymphgefässe der Lunge, zugleich ein Beitrag zur Erklärung der Baucherscheinungen bei Pneumonie. Dtsch.Z. Chir., 119, 107.

Grainger, R. G. (1958). Interstitial pulmonary oedema and its radiological diagnosis. A sign of pulmonary venous and capillary hypertension. Brit. J. Radiol., N.S., 31, 201.

Harold, J. T. (1952). Lymphangitis carcinomatosa of the lungs. Quart. J. Med., N.S., 21, 353

Hauser, T. E., and Steer, A. (1951). Lymphangitic carcinomatosis of the lungs: six case reports and a review of the literature. Ann. $\times$ intern. Med., 34, 881.

Jarcho, S. (1936). Diffusely infiltrative carcinoma. Arch. Path., 22, 674.

Kerley, P. (1951). In A Text-book of $X$-ray Diagnosis, 2nd ed., ed.Shanks, S. C. and Kerley, P., Vol. 2, pp. 395-408. Lewis, London.?

evin, B. (1959). Subpleural interlobular lymphectasia reflecting metastatic carcinoma. Radiology, 72, 682.

Lorenz, H. (1921). Lymphogene Lungencarcinose. Fortschr. Röntgenstr., 28, 430

Morgan, A. D. (1949). The pathology of subacute cor pulmonale in diffuse carcinomatosis of the lungs. J. Path. Bact., 61, 75.

Mueller, H. P., and Sniffen, R. C. (1945). Roentgenologic appearance and pathology of intrapulmonary lymphatic spread of metastatic $=$ and pathology of intrapulmonary lymphat

Nohl, H. C. (1962). The Spread of Carcinoma of the Bronchus, p. 31. Lloyd-Luke, London.

Raynaud, M. (1874). Mémoire sur l'angioleucite généralisée des $\mathrm{N}$ poumons. Bull. Soc. méd. Hôp. Paris, 2nd series, 11, 66.

Rouvière, H. (1932). Anatomie des Lymphatiques de l'Hcmme, p. 217. N

Masson, Paris.
Short, D. S. (1956). Radiology of the lung in left heart failure. Brit $\mathcal{X}$

Heart J, 18, 233 . Butterworths, London.

Smith, J. L. (1909). A case of cancer of the pylorus. Brit. med. J., 2, 861.

Trapnell, D. H. (1963). The peripheral lymphatics of the lung. Brit. $\square$ J. Radiol. N.S., 3f, 660.

Troisier, E. (1873). Cancer de l'estomac; cancer secondaire des poumons. Lymphangite pulmonaire généralisée. Bull. Soc. anat. (D Masson, Paris, 48, 834.

Virchow, R. (1855). Trois observations de tumeurs épithéliales généralisées. Gaz. méd. Paris, 3 ser., 10, 208.

Wagner, E. (1863). Der Krebs der Lymphgefässe der Pleura und dero Lungen. Arch. Heilk., 4, 538, quoted by Jarcho, S. (1936).

Wu, T. T. (1936). Generalised lymphatic carcinosis ("Iymphangitis carcinomatosa") of the lungs. J. Path. Bact., 43, 61. 